\title{
Consummatory response latency and the stimulus-reinforcer relation in autoshaping
}

\author{
BRUCE L. BROWN, DAVID A. COLEMAN, JR., and SARA ELEFANT \\ Queens College, CUNY, Flushing, New York
}

\begin{abstract}
Autoshaping procedures with pigeons were used to assess the susceptibility of unconditioned response (UR) activity to Pavlovian relations between stimulus and reinforcer events. Foodpeck latency (a measure of UR activity) was investigated as a function of the interval between stimulus (keylight) and reinforcer (grain) presentations, and of the stimulus-reinforcer contingency, that is, the conditional probabilities of reinforcer delivery in the presence and absence of the stimulus. Four experiments indicated that food-peck latency was sensitive to both manipulations. Generally, conditions that led to higher keypeck rates were associated with shorter latencies. Thus, UR potentiation was demonstrated. However, when the bird's location prior to grain delivery was fixed by imposing a keypeck-reinforcer contingency, UR potentiation vanished; it then reappeared when the location constraint was removed. Visual observations supported the conclusion that food-peck latency effects were mediated by approach/withdrawal tendencies generated by the stimulus-reinforcer relation. Implications of these results for expectancy theory are discussed.
\end{abstract}

There is substantial evidence that keypeck behavior engendered in the autoshaping procedure with pigeons (Brown \& Jenkins, 1968) depends upon Pavlovian relations between the signal (CS) and reinforcer (US) events, such as the illumination of a key and the presentation of grain (Gibbon \& Balsam, 1981; Schwartz \& Gamzu, 1977). A prevalent theoretical view holds that such relations generate CS-US associations, or expectancies, which mediate conditioned responding. Thus, the CS has been conceived as a Tolmanian sign-object (Hearst \& Jenkins, 1974), or a learned releaser (Woodruff \& Williams, 1976) that controls preparatory behavior that is specific to the US. In addition, CS-US associations have been invoked as mediating a variety of stimuluscontrol phenomena including higher order conditioning (Burt \& Westbrook, 1980), blocking (Leyland \& Mackintosh, 1978), and matching-to-sample (Edwards, Jagielo, Zentall, \& Hogan, 1982) in pigeons.

Traditionally, the consequences of Pavlovian procedures have been sought in examination of behavior during the CS. However, from the vantage point of expectancy theory, behavioral effects might also be found during the presentation of the US. That is, it may be supposed that an expected reinforcer would receive a different reaction from one that is unexpected, or surprising (Kamin, 1969). The present study pursued this implication by investigating US-directed behavior, that is, consummatory activity, in autoshaping.

This research was supported by PSC/BHE Grant 12381 and by NIH Grant RR07064 awarded to the first author. Requests for reprints should be sent to Bruce L. Brown, Department of Psychology, Queens College, Flushing, New York 11367.
The relevance to expectancy theory of behaviors occasioned by the US was recognized in early learning studies (Cowles \& Nissen, 1937; Hilgard \& Marquis, 1940; Tinklepaugh, 1928). For instance, "representational" learning was invoked by Tinklepaugh (1928) in a delayed response procedure with monkeys. He found that subjects refused to accept a reward (e.g., lettuce) on a correct trial when it differed from that (e.g., banana) presented on all previous trials, although under other circumstances lettuce was an effective reward. However, differences in consummatory behaviors may have arisen from differences in preference for each reinforcer. An alternative strategy is to manipulate factors other than reinforcement, and examine effects upon unconditioned response (UR) tendencies while holding the US constant. Research following this strategy has disclosed both decremental and incremental effects upon the strength of the UR during conditioning.

Decremental effects, largely confined to human studies, have been described as diminished UR amplitude on CS-signaled US presentations, as compared with unsignaled trials, and as recovery of the UR during unsignaled trials following a series of signaled (conditioning) trials. Such decremental effects have been reported for eyelid conditioning with an airpuff US (Hupka, Kwaterski, \& Moore, 1970; Kimble \& Dufort, 1956; Kimble \& Ost, 1961) and for the galvanic skin response with shock US (e.g., Baxter, 1966; Grings \& Schell, 1969; Kimmel \& Pennypacker, 1962; Morrow, 1966). Recently, UR diminution has been reported in conditioning with rabbits (Donegan, 1981), which showed attenuated eyeblink and gross body-movement URs when a shock US was preceded by a positive CS as opposed to negative CS or no-CS trials. 
Diminution and recovery of UR have been interpreted as conditioned inhibitory phenomena (Kimmel, 1966). An alternative account has focused upon perceptual learning (Grings, 1960), and views UR recovery as a response to the disparity occasioned by the shift from a familiar signaled US to a novel unsignaled US. A similar idea has been proposed recently in a more formal theoretical framework by Wagner $(1976,1978)$. In brief, stimulus events such as USs are processed to the extent that they are surprising, that is, are not already represented in short-term memory. A US may be activated or "primed" in memory either by its own recent presentation or by a CS with which it has been paired; in either case, the result is the same-a subsequent US presentation is rendered less surprising and results in diminished processing. Accordingly, UR diminution during conditioning represents reduced processing of an increasingly expected US, via CS-generated priming, while UR recovery on US-alone trials represents enhanced processing of the now less expected US.

It might be predicted intuitively that an expected US would receive an enhanced reaction. While the data on incremental effects, and their associative status, are less well documented then are UR decrements, there is evidence, largely from animal studies, of UR potentiation in conditioning. Studies of the nictitating membrane response in rabbits have shown augmented UR amplitude (Grevert \& Moore, 1970; Hupka et al., 1970) and a decrease in UR latency (Salafia, Daston, Bartosiak, Hurley, \& Martino, 1974; cf. Mowrer, 1940) during conditioning. Both an increase in UR rate and a decrease in latency have been reported during conditioning for the rabbit's jaw-movement afterdischarge response to a water US (Sheafor \& Gormezano, 1972). The direction of the UR effect does not appear to be response-specific. Donegan (1981) reported a shift from decremental to incremental effects as US intensity decreased in rabbit eyelid conditioning.

Indirect measures also provide support for incremental effects. For example, Zamble (1973) found substantially greater food intake among rats maintained on a schedule of signaled feedings than among rats given unsignaled food. In addition, threshold measurement of the eliciting US has suggested UR potentiation. In their human defensive conditioning study employing shock to the hand as the US, Spooner and Kellogg (1947) adjusted US intensity to prevent adaptation to shock. Among groups differing in CS-US intervals, backward- and simultaneous-pairing groups required higher intensities than did forward groups, a finding in line with CR magnitude measures in the same subjects. More recently, in a study of leg-flexion conditioning in dogs, Thomas (1971) paired an auditory CS with direct stimulation of motor cortex as the US in a discrimination conditioning procedure. On test trials, the positive CS presented together with threshold cortical stimulation produced a greater tendency of leg flexion than threshold stimulation alone, as a result of the pairing procedure. The two foregoing outcomes are readily interpretable in terms of enhanced US expectancy.

The purpose of the present study was to extend the investigation of UR modification to the autoshaping procedure with pigeons, to assess the associative nature of the phenomenon, and to examine its theoretical implications. Specifically, foodpeck latency was studied as a function of the CS-US interstimulus interval (ISI) in Experiments 1 and 2 and the CS-US contingency in Experiments 3 and 4 . These two variables are known to exert powerful control over key-directed behavior. We report that both manipulations produce incremental effects upon food-directed behavior. While the direction of the effect is congruent with expectancy theory, the evidence indicates (Experiment 4) that the effect is indirect, and may be understood in terms of principles governing key-directed behavior.

\section{EXPERIMENT 1}

In this experiment, the relation between CS and US was manipulated by varying the ISI. Pigeons were exposed to an autoshaping procedure in which ISI values of $1,2,5,15$, and 45 sec varied across trials; each value was associated with a different key color.

\section{Method}

Subjects. Five experimentally naive White Carneaux hen culls were maintained at $80 \%$ of their free-feeding weights.

Apparatus. A standard-size chamber $(36.5 \mathrm{~cm} \mathrm{~h} \times 30.5 \mathrm{~cm} \mathrm{w}$ $\times 35 \mathrm{~cm} \mathrm{d)} \mathrm{was} \mathrm{constructed} \mathrm{with} \mathrm{stainless-steel-lined} \mathrm{walls} \mathrm{and}$ ceiling and a three-key intelligence panel with only the center key exposed. The clear Lucite key $(1.5 \mathrm{~cm}, 0.2 \mathrm{~N}$ force) and hopper aperture were located 25.3 and $12.5 \mathrm{~cm}$ from the floor, respectively. A houselight, directed toward the ceiling, was centered at the top of the intelligence panel. The chamber was used in all experiments.

Five key colors, ranging from green-blue to red $(501,538$, 555,576 , and $606 \mathrm{~nm}$ ), were projected through Wratten filters provided in a rear-projection display unit (IEE, Model 0010-01$3043-1820 x$ ). The output of an earphone mounted beneath the food tray served as the first stage of a transducer which converted food pecks into pulses (Bertsch \& Becker, 1973). Foodpeck latency, timed from the onset of grain presentation to the first peck to grain, was measured to the nearest $.05 \mathrm{sec}$. Latency measures obtained with the impact sensor were compared with those obtained with the use of a photosensor beam directed across the hopper cavity. The correlation between the two measures was .88. The experiment was controlled by an 8-channel tape reader and electromechanical devices located in one room; birds were run in an adjacent room with white noise continuously present.

Procedure. The birds were placed in the lighted chamber for $15 \mathrm{~min}$ on a habituation day. On the following day, magazine training commenced. In the first session the birds were permitted to eat from an overfilled, lighted food tray for $15 \mathrm{sec}$; thereafter, 20 tray presentations occurred at about 60 -sec intervals for a maximum duration of $10 \mathrm{sec}$ prior to the first peck to grain, after which grain was available for an additional 4 sec. If peck latency was $10 \mathrm{sec}$ or shorter on 9 of 10 trials, maximum grain presentation in the next 20 -trial session was reduced to $4 \mathrm{sec}$ prior to the first peck. If criterion was met, grain was presented in the following session for 30 trials at the same interreinforcer intervals and constant duration (3.5 sec) as those prevailing during subsequent autoshaping sessions. Criterion on this final 
magazine training condition was 27 "eats" in 30 trials in two successive sessions. In sum, the criterion for magazine training required a minimum of four sessions. Criterion was met within 5 to 10 sessions by all birds but one, which received 33 sessions. The houselight was illuminated except during food presentations.

Daily autoshaping sessions, initiated on the next session, consisted of paired presentations of keylight and grain, occurring independently of the bird's behavior. On each trial, illumination of the key and grain delivery (hopper operation and illumination) occurred in a nonoverlapping sequence, with the keylight on throughout the ISI. In an attempt to reduce the likelihood of hopper-directed activity (goal-tracking) prior to food delivery, the houselight was extinguished during both keylight and grain presentation.

The ISI durations of $1,2,5,15$, and $45 \mathrm{sec}$ were differentially coded by the five key colors. The relation of ISI to color differed among subjects so that the two stimulus dimensions (color and ISI) were balanced in a $5 \times 5$ Latin square design.

Sessions consisted of $\mathbf{3 0}$ trials presented as six cycles of the five ISI values in random order. Training was conducted in random blocks of five sessions that differed in the order of ISIs. Different sequences were generated for each bird. Intertrial intervals (ITI), reckoned from grain offset to keylight onset and ranging from 40 to $80 \mathrm{sec}$ in 10-sec steps (mean: $60 \mathrm{sec}$ ), were assigned randomly to the five trials in a cycle, with the restriction that within a session the mean ITI preceding any ISI fell between 50 and $70 \mathrm{sec}$. Training was conducted for a total of 10 five-session blocks.

Food-peck latencies on initial trials of a session were more variable than subsequent values. Therefore, data from the first five-trial cycle of a session were routinely discarded. Keypecks emitted during hopper presentation could have registered as food pecks by activating the impact sensor. Examination of a sample of such trials revealed no reduction in latency. Nevertheless, as a precaution, latencies on such trials were also discarded. This criterion resulted in a loss of fewer than $4 \%$ of all trials. Latency on a trial in which no food peck occurred was scored as $3.5 \mathrm{sec}$.

\section{Results}

Food-peck latency. Figure 1 depicts group mean latency plotted for each ISI over the course of the $\mathbf{5 0}$ training sessions. Two trends are evident: First, latency decreased over session blocks, a significant effect in an ISI $X$ block ANOVA $[F(9,36)=8.54, \mathrm{p}<.01]$. Second, food-peck latency was systematically related to the ISI $[F(4,16)=5.7, p<.01]$. Mean latency was shorter at the $2-$ and $5-\mathrm{sec}$ ISI values than at bracketing values, a pattern reflected as a reliable quadratic trend $[F(1,4)=$ $11.18, \mathrm{p}<.05]$.

The ISI effect does not appear to vary with training, and the ISI $X$ block interaction was not reliable $[F(36,144)=1.23, p>.10]$. The results of the first training session were examined for evidence that rapid acquisition of ISI control may have occurred within Block 1. However, the ISI effect was also present on that session $[F(4,16)=5.48, p<.01]$.

Pecks to the key. All birds exhibited keypecking in the presence of the signal, but not during the ITI. Mean peck rate over the final three blocks $(8,9$, and 10$)$ was $3,21,29,12$, and 2 responses/min for ISI values of $1,2,5,15$, and $45 \mathrm{sec}$, respectively. An analysis of variance (ANOVA) indicated that differences among rates were reliable $[F(4)=3.0, p=.05]$. The rate data replicate findings previously reported for within-subject

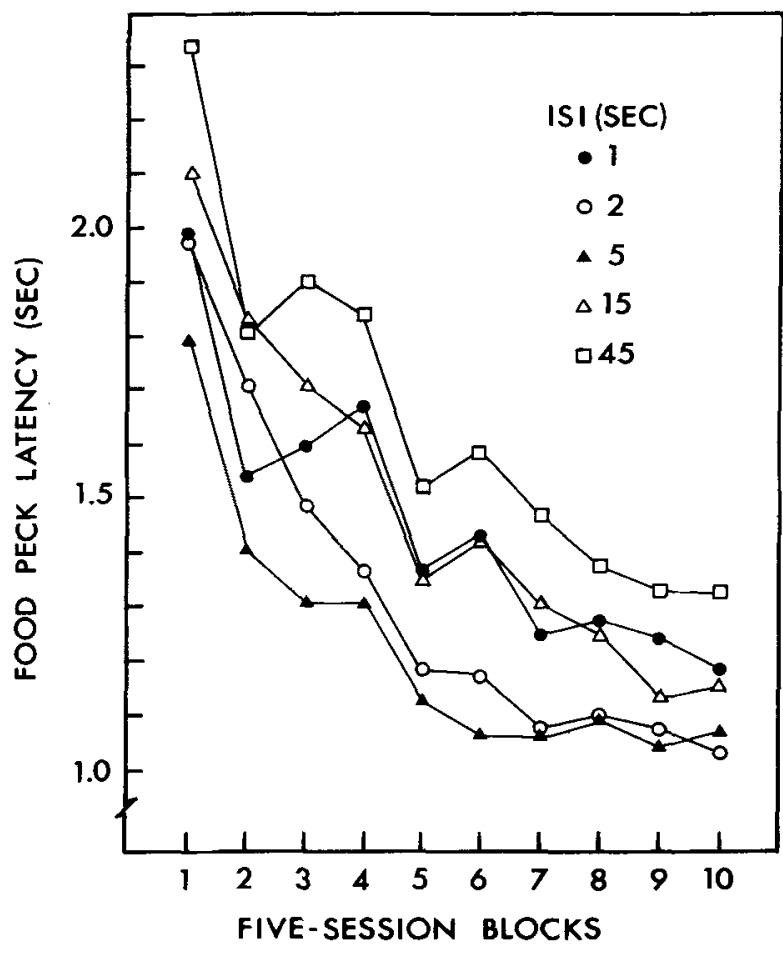

Figure 1. Group mean food-peck latency as a function of session blocks. Parameter is the interstimulus interval.

manipulation of color-coded ISI (Perkins, Beavers, Hancock, Hemmendinger, Hemmendinger, \& Ricci, 1975) for the range sampled in common. That study reported a decrease in rate as ISI increased from 4 to $32 \mathrm{sec}$.

\section{Discussion}

The decline in food-peck latency across sessions is consistent with results of other Pavlovian preparations (e.g., Salafia et al., 1974) showing UR facilitation during conditioning. Such a finding is compatible with a learned expectancy account. However, the mechanism underlying facilitation remains to be specified. The latency decline could reflect potentiation of eating behavior itself, or it could represent an indirect effect resulting from behaviors occasioned by the CS. The present results do not distinguish between these alternatives, which are explicitly studied in Experiment 4.

A second issue concerns the associative status of the latency effect. Although Sheafor and Gormezano (1972) reported an increase in UR strength during conditioning, they observed no difference between groups receiving paired or unpaired CS and US presentations. In that study and in the present one, UR facilitation alone could reflect sensitization or other nonassociative effects.

In the present study, the fact that latency varied with ISI, and in a manner correlated with keypecking, does suggest involvement of associative factors related to CS 
cues. That is, key-color signals may have assumed control of UR latency through their association with different delays, or time remaining (Gibbon \& Church, 1981), to reinforcement. However, other accounts are possible. For example, the interreinforcer interval, which was confounded with ISI could have controlled UR latency. Or control may have been exerted by time elapsed from the start of a trial (i.e., houselight offset plus keylight onset), irrespective of key color. The fact that an ISI effect was evident at the outset of training implies control by factors other than signaled delay to reinforcement. The possibility remains, however, that different delays, which were tagged by ISI color codes, acquired control during subsequent sessions. The question of acquired control by signaled delays was addressed in the next experiment.

\section{EXPERIMENT 2}

The present study, a partial replication of Experiment 1 , assessed the role of color cues paired with different ISIs. This was achieved by introducing a change, after some training, in the assignment of colors to ISIs. If variation in food pecking with ISI is unrelated to color, then this behavior should remain invariant following such a change.

If color did control food-peck latency in Experiment 1, a procedural problem in that study poses a question concerning the etiology of such control. A critical datum was the appearance of an ISI effect at the outset of training. Since grain was presented for a fixed duration, the initial ISI effect produced a systematic relation between key color and duration of the bird's access to grain. That is, ISI and amount of reinforcement were confounded. Thus, an initial nonassociative ISI effect could have led to acquired control of UR latency by variation in signaled magnitude, rather than delay, of reinforcement. In the present study, only signaled delay varied. Reinforcer duration was held constant by providing access to grain for a fixed time interval following the first peck to grain.

\section{Method}

Subjects. Six experimentally naive Carneaux hen culls were maintained at $75 \%$ of free-feeding weight.

Procedure. Magazine training was conducted in two phases. In the first phase, a bird was permitted to eat from an overfilled food tray for 20 sec. On subsequent trials, eating time was reduced and interfood interval was increased in steps until grain was presented every $30 \mathrm{sec}$ on the average with 2-sec access following the first peck to grain. The criterion for exiting this phase was 9 eats with a maximum latency of $5 \mathrm{sec}$ on 10 successive trials. In the next phase, sessions consisted of 32 unsignaled grain presentations at the same interfood intervals and grain access duration as those during training. The eating latency criterion was $5 \mathrm{sec}$ or less on at least 29 trials. All birds met the magazine training criterion within 4 days. One additional magazine training session was given following the final criterion session.

Training consisted of paired presentations of the keylight signal and grain. The food tray was presented for a maximum duration of $20 \mathrm{sec}$; access to grain was always 1 sec timed from the first peck to grain. The relations among houselight, keylights, and hopper activation were otherwise the same as those in Experiment 1.

In each daily training session, half the trials were signaled with a 5-sec ISI and the other half with a 40-sec ISI. For three of the birds (short-red group), the short and long ISIs were coded by red and green colors, respectively; for the other three birds (short-green group), the color-ISI relation was reversed. The ITI was either 40 or $80 \mathrm{sec}$ in duration. Each session consisted of 32 trials presented as eight random blocks of four trials containing each of the four possible combinations of ISI and ITI durations. Two such sequences were generated, and differed only in that the values of the ISIs were reversed. The sequences were presented in random order within two-session blocks.

The experiment was run in three phases. Phase 1 was run under the training conditions described above. In Phase 2 , the relation of color and ISI that held in Phase 1 was reversed. In Phase 3, the color-ISI relation was reversed again. Each phase was in effect for eight sessions.

For purposes of analysis, data from the first four trials of a session were routinely discarded. In addition, a trial was discarded if latency was longer than $10 \mathrm{sec}$; this criterion resulted in a minimal loss of data, that is, $1 \%$ of all short- or long-ISI trials. One bird in the short-red group missed Session 8; for that bird, latencies on Session 7 were taken for Session Block 4.

\section{Results and Discussion}

Food-peck latency. Figure 2 depicts group mean food-peck latency for the six birds as a function of session blocks. As the figure indicates, Phase 1 replicated the acquisition results in Experiment 1: Group mean latencies for the 5-and 40-sec ISIs over Blocks 1 to 4 (32 trials per block on each ISI) in the present study were comparable to those for the 5 - and $45-\mathrm{sec}$ ISIs over Blocks 1 to 4 (30 trials per block on each ISI) in Experiment 1 (cf. Figure 1). An analysis of variance (ANOVA) of latency for group (short-red vs. shortgreen) $\times$ ISI $\times$ block revealed reliable effects of ISI

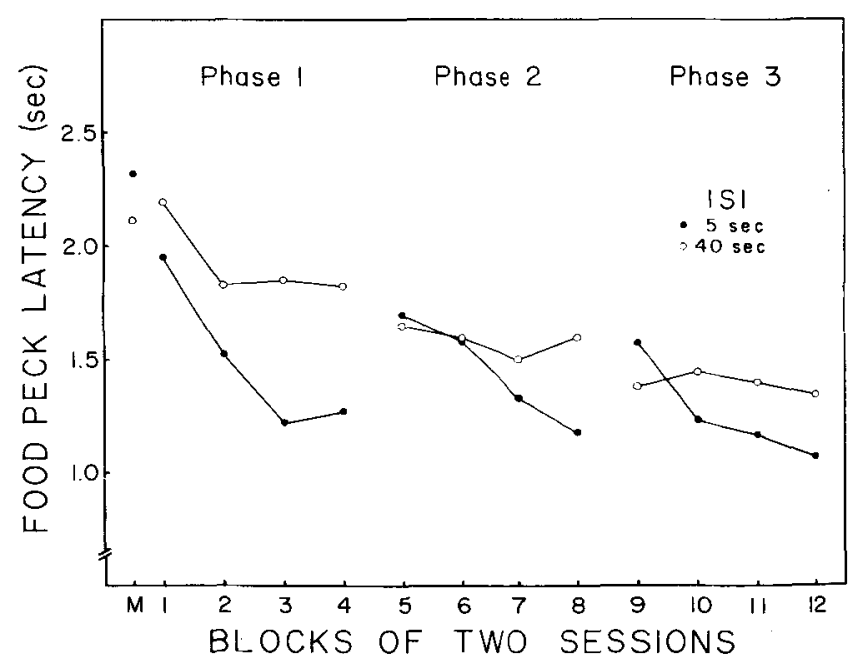

Figure 2. Mean food-peck latency across session blocks on short and long ISI trials. Color-ISI relations were reversed between phases. $M$ indicates final magazine training session. 
$[F(1,4)=8.88, p<.05]$ and block $[F(3,12)=10.68$, $\mathrm{p}<.01]$ only. In this and subsequent analyses, none of the group effects was reliable.

As in Experiment 1, the ISI effect on food-peck latency in Phase 1 appeared at the outset of training, and showed no reliable growth over sessions. However, evidence of associative control by delay to reinforcement was provided by the reversal of color and ISI relations between phases. At each reversal (Blocks 5 and 9), an increase in latency occurred between the two pre- and postswitch blocks on the 5 -sec ISI trials, but not on the 40-sec trials. That is, latency increased when the shorter ISI was signaled by the old long color. An ANOVA for block (pre- vs. postswitch) $X$ ISI $X$ group $X$ reversal (first vs. second) showed a reliable decrease in latency between reversals, but more importantly a reliable ISI $X$ block interaction $[F(1,4)=8.42, p<.05]$ that was due to an increase in latency between blocks on the 5 -sec trials $[t(4)=4.82, p<.01]$, but no change on the 40 -sec value $(\mathrm{t}<1)$.

The emergence of an ISI effect in both Phase 2 and Phase 3 argues against the possibility that the effect seen in Phase 1 reflects merely the preservation of initial latency differences. On the first block of both phases, latency on the 5-sec trial was slightly longer than that on the 40-sec trial, but by the fourth block, the 5-sec trial latency was substantially shorter. An ANOVA (phase $X$ ISI $X$ block $X$ group) showed in addition to a reliable decline in latency across blocks, a significant ISI $\times$ block interaction $[F(3,12)=5.44, p<.05]$. Individual comparisons indicated no reliable ISI effect on the first block of a phase $(t<1)$, but a significantly shorter latency at the $5-\mathrm{sec}$ ISI on the fourth block $[\mathrm{t}(4)=2.24$, $p<.05]$. Further analysis suggested the emergence of a signaled delay effect despite potential opposition by initial latency differences. In 7 of the 12 total reversals across both phases and all birds, latency on the 5 -sec trial was longer than on the 40 -sec trial on the first reversal block, yet, in 6 of the 7 cases, that difference reversed by the fourth block ( $p=.05$, sign test), and in the one exception the difference reversed following extended training (Session 29) for one bird in Phase 3. The preceding observations indicate that (1) associative effects of ISI are detectable when reinforcer duration is held constant, and (2) such delay-to-reinforcement effects do not depend upon initial, presumably nonassociative, latency differences between ISIs.

The possibility was raised previously that one of the factors contributing to the initial ISI effect was the interfood interval. Figure 2 shows that, in the present study, the effect did not appear on the last magazine training session ( $M$, in the figure) when grain was unsignaled, but presented at intervals corresponding to those on 5- and 40-sec trials. When latencies on the magazine training session and the first training block were analyzed, the interaction between "ISI" and signaled vs. unsignaled sessions was reliable $[F(1,4)=11.95$, $\mathrm{p}<.05]$. Thus, the initial ISI effect is not attributable to interfood interval, but depends upon the presence of signaled time intervals.

Keypeck rate. Keypecking activity was low throughout the experiment. No pecking was observed in three of the birds in Phase 1. In order to evaluate key-directed activity in the temporal vicinity of grain presentation, we determined the peck rate during the last 2.5 -sec portion of the signal on all trials in Phases 2 and 3 . During that interval on 512 trials, four birds produced no more than one response and the other two gave totals of 8 and 43 responses. The low rates were related in part to the reversals, which produced abrupt declines in pecking.

\section{EXPERIMENT 3}

The results of Experiments 1 and 2 indicate control of eating latency by the CS-US relation defined in terms of the ISI. It is apparent, however, that properties of the ISI, exclusive of the CS-US relation, also controlled latency. The present study sought to assess Pavlovian control of latency in an alternative, and more straightforward, manner. This was achieved by manipulating the CS-US contingency (Rescorla, 1967), that is, the difference between the conditional probabilities of food given keylight presentation and food given no keylight. The question is whether eating latency on signaled trials will differ between contingent and noncontingent conditions.

One purpose of this study was to extend the range of Pavlovian procedures influencing latency. A second was to provide a suitable procedure for evaluating the mechanism underlying the effect. In the present studies, latency variation could reflect either different strengths of eating tendencies or differences in prefood behavior, possibly involving the bird's position in the chamber. The contingency manipulation in the present study provided the basis for a direct test of these alternatives in Experiment 4.

\section{Method}

Subjects. Twelve naive Carneaux hen culls, maintained at $75 \%$ of free-feeding weight, were randomly assigned to three groups $(n=4)$.

Apparatus. Eating behavior in the present study was monitored as insertion of the bird's head into the hopper aperture was detected by the interruption of a light beam directed across the hopper cavity. The photobeam replaced the impact sensor in order to eliminate the possible measurement problem posed by keypecks occurring during food presentation. During some sessions, a flat black liner, constructed of $1.3-\mathrm{cm}$-thick plywood, covered all interior surfaces of the chamber except for the mesh floor. Openings in the liner were present at locations of houselight, magazine aperture, speaker, exhaust fan, and when necessary, the key.

Procedure. Magazine training was initiated by presenting grain in an overfilled, illuminated food tray, which remained raised for $20 \mathrm{sec}$ after the bird's head broke the photobeam. Grain was then presented at 15 -sec intervals for maximum durations of $30 \mathrm{sec}$. Duration of access to grain was $4 \mathrm{sec}$ after the beam was broken. When the bird had eaten on five successive trials within the alloted $30 \mathrm{sec}$, access time was reduced from 4 to $2 \mathrm{sec}$ for 20 additional trials and ITI was increased to a 
mean of $30 \mathrm{sec}$. Birds were returned to the 2 -sec trials on the next day if they failed to meet a criterion of 9 eats in 10 of those trials. All birds met criterion within two sessions.

The experiment was conducted in three phases: pretraining, training, and testing. In each phase, daily sessions were composed of 300 successive $10-\mathrm{sec}$ time bins. At the end of each bin, grain was either presented or not. Bin timing was suspended during grain presentation. Maximum US duration remained $30 \mathrm{sec}$, and access time was reduced to $1 \mathrm{sec}$.

Pretraining was run as an extension of magazine training to enhance reliability of approach to grain. Unsignaled grain was presented for five sessions at fixed random bin locations. The number of grain deliveries in Sessions 1-2 and 3-5 were 60 and 12 per session, respectively. In order to reduce the likelihood of blocking by background cues (Tomie, 1976), we conducted magazine training and pretraining in the presence of the black chamber liner, which was removed prior to the next phase.

Treatment differences were introduced in the training phase. In each session, the key was illuminated with a red light on 60 bins ( 1 trials) and was dark on the remaining 240 bins (S0 trials), with S1 trials distributed in a fixed random order. Contingencies between keylight and grain were determined by the probabilities (p) of grain on each trial type. For the experimental group (Group E), a positive contingency was arranged by setting a probability gate to $p=.20$ in $S 1$ bins and $p=0$ on S0 bins, yielding an expected frequency of 12 reinforcers per session. Two control groups were exposed to zero keylightgrain contingencies. For Group $\mathrm{C} 60$, p was set at .20 in both $\mathrm{S} 1$ and $\mathrm{S} 0$ bins, yielding 60 expected reinforcers per session. For the other control condition, Group C12, p was set at .04 in both bin types, yielding a zero contingency, and the same expected total frequency of reinforcers as in Group E. Training was conducted for 10 sessions.

The testing phase was conducted in the next five sessions, during which all birds were exposed to one of the zero-contingency conditions. The value of $p$ was set at .20 for both bin types, as in training for Group C60. A new set of S1 bin locations was randomiy determined for this phase.

In all three phases, the houselight was continuously illuminated except during grain presentation.

\section{Results}

Food-peck latency. Figure 3 presents group mean food-peck latencies in seconds, plotted against sessions in each phase. Daily mean latencies were computed for each bird from all grain presentations except the first signaled and unsignaled presentations of a session and any latencies longer than $5 \mathrm{sec}$. The rejection rate on the basis of the $5-\mathrm{sec}$ criterion was about $1 \%$ of all latencies.

The first panel in Figure 3 shows performance during pretraining, prior to differential treatment of groups. Eating latency on these unsignaled trials lengthened when US frequency was reduced from 60 presentations on the first two sessions to 12 on the next three [t(11) = $2.88, \mathrm{p}<.02]$.

The second panel depicts performance during training for Groups $\mathrm{E}$ and $\mathrm{C} 60$ on signaled presentations only. No data are plotted for Group $\mathrm{C} 12$ because signaled trials were too infrequent to permit determination of daily means. Both groups exhibited shorter latencies across sessions, but the decrease was greater for Group E than for Group C60. An ANOVA yielded a reliable days effect $[F(9,36)=7.24, p<.01]$ and a days $X$ groups interaction $[F(9,36)=3.31, p<.01]$. Further tests showed no difference between groups on Day $1[\mathrm{t}(6)=$

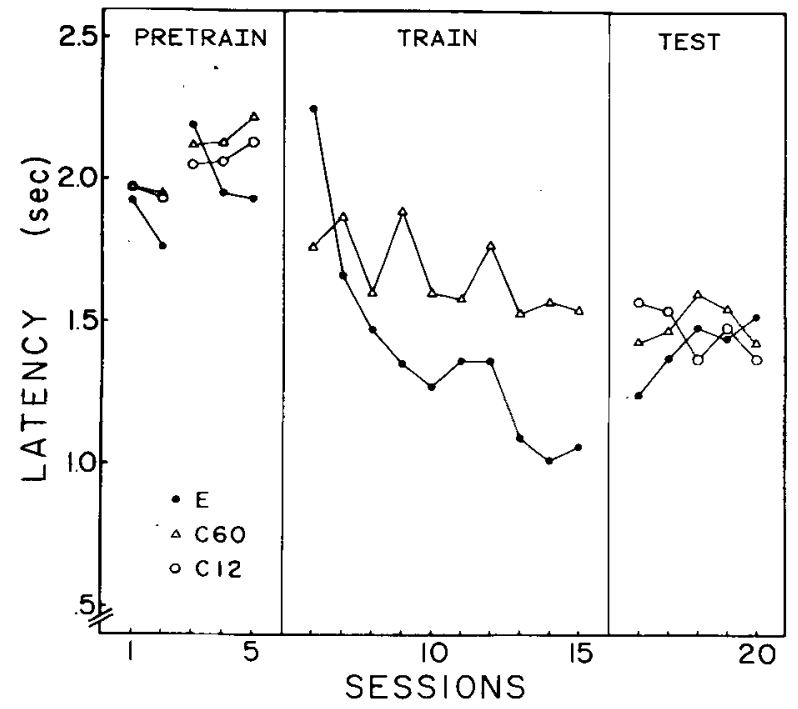

Figure 3. Mean food-peck latency during pretrain, train, and test phases for experimental (E) and control (C60 and C12) groups. Data in train and test are for signaled trials only.

$1.23]$, but a reliable difference by Day $10[t(6)=2.92$, $\mathrm{p}<.02]$.

The third panel in the figure shows latencies on signaled trials for the three groups during the testing phase, in which all birds were placed on a zero contingency condition. The results indicate that when the contingency differences were eliminated, performance differences disappeared. While a days $X$ groups ANOVA revealed no reliable effects during testing, trends were in the expected direction; therefore, an alternative analysis was performed. A linear fit to the latencies of each bird over the five test sessions was obtained, yielding a singleslope score for each subject. Mean slopes for Groups E, $\mathrm{C} 60$, and $\mathrm{C} 12$ were $1.3, .1$, and $-1.0 \mathrm{sec} /$ day, respectively. An ANOVA of slopes showed a reliable difference among group means $[F(2,9)=4.87, p<.05]$. Contrast tests indicated that the slope for Group $\mathrm{E}$ was greater than that for the two control groups combined $[F(1,9)=8.69, p<.05]$, and that the control group slopes did not differ reliably $[F(1,9)=2.48]$. These comparisons suggest that latency differences that emerged with training disappeared gradually during testing when treatment differences were eliminated.

Contingency effects were also reflected in latencies on unsignaled food presentations. Figure 4 presents group mean latencies on both signaled and unsignaled trials for the final training day and the five test sessions. On initial test days, unsignaled latency for Group E exceeded those for the control groups, but fell to control levels across test days. These results were reflected as a reliable days $X$ groups interaction $[F(8,36)=5.40$, $\mathrm{p}<.01]$. Latencies on the first 2 days were reliably longer for Group $\mathrm{E}$ than for the two control groups $[t(10)=2.37, p<.05]$, which did not differ reliably 


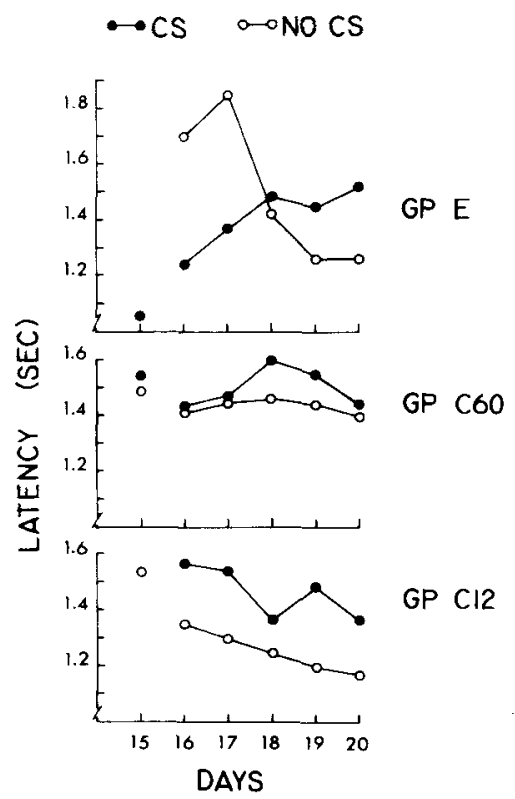

Figure 4. Mean food-peck latency on signaled (CS) and unsignaled (NO-CS) grain presentations during the final training session and the test phase.

from each other. There were no reliable group differences on the final 2 test days. An additional aspect of the data concerns the comparison between signaled and unsignaled food presentations. Figure 4 shows that in both control groups, latencies on signaled trials were longer than those on unsignaled trials. A group $X$ stimulus $X$ day ANOVA of those data indicated an effect of the signal $[F(1,6)=11.10, p<.05]$ with no reliable interactions. Thus, in the absence of a keylight-grain contingency, the keylight served to lengthen eating latency. This was not generally true for Group $E$, for which latencies were longer on unsignaled than on signaled trials during the first 2 test days $[t(3)=4.38$, $p<.05]$. At the end of the test phase, performance was similar to that of the control groups.

Keypeck rate. All birds in Group E pecked the key during signaled periods. Mean rate over the last five training sessions was 26 responses/min (range: 4-74). Rates declined for all these birds during testing. No keypecking was observed in any of the control birds.

\section{Discussion}

The results indicate that the latency to eat signaled food was shortened under a positive signal-grain contingency in comparison with zero-contingency control conditions. Thus, UR facilitation is indicated by the contingency manipulation. During training, Groups E and C60 experienced different overall frequencies of grain presentation in addition to different contingencies. However, it is unlikely that the effect in the training phase was based upon differences in rate of grain presentation, since the pretraining data suggest that lower rates yield longer latencies, an effect in the opposite direction to that observed in training. In addition, rate of grain presentation was identical for Groups E and C12 during training and testing, yet the trends of latency changes across test sessions were in the opposite directions for those groups.

Aspects of these results may be understood in terms of current Pavlovian theory. For instance, in the RescorlaWagner model (Rescorla \& Wagner, 1972), "contingency" effects are interpreted in terms of the role of both signal and background cues which divide a limited amount of associative value between them. In accord with the present results, the model holds that associative value becomes bound exclusively to the background in zero-contingency control conditions and to the signal in the experimental condition. This analysis assumes that value accruing to the signal controls a form of behavior (e.g., keypecking) that is not controlled by value assigned to background cues. However, for Group E, latency during the test phase on unsignaled trials varied in a manner that reflects expected growth of value to the background cues. This suggests that, unlike keypeck rate, food-peck latency is controlled by a common mechanism during both signal and nonsignal periods.

\section{EXPERIMENT 4}

While the results of Experiments 1-3 demonstrate control of eating latency by Pavlovian relations between signal and food, the mechanisms underlying such control remain to be specified. Recent theoretical accounts of conditioning have focused upon the role of CS-US relations as establishing expectancies that have motivational properties (e.g., Bindra, 1974; Bolles, 1972). According to such theories, expectancy serves, in interaction with prevailing stimulus conditions, both to select behavior and to motivate whatever behavioral tendencies it produces. In the autoshaping situation, the same expectancy of food that controls keypecking could enhance the strength of pecking at food when it becomes available. Hearst and Jenkins (1974), in considering an expectancy-releaser model, were explicit on this point: "We may suppose that any signal which regularly precedes the appearance of a specific consummatory stimulus, such as food or water, produces a high state of readiness to perform the appropriate consummatory behavior. Although this heightened readiness is a product of learning and depends upon a relation between external events, it presumably has motivational properties similar to those associated with certain internal changes. Specifically, in the presence of the signalling stimulus, the threshold for evocation of the consummatory responses would be lowered and suboptimal stimuli become capable of evoking the responses.... Because of its predictive relation to the consummatory stimulus, 
[the lighted key] induces a high state of readiness to perform the appropriate consummatory responses" (p. 31).

The present latency results may be understood, accordingly, as the potentiation of consummatory behavior by the expectancy of food.

An alternative to a motivational interpretation is that the CS-US relation may exert control of food-peck latency only indirectly by its influence upon behavior occurring during the signal. For example, pigeons tend to approach or withdraw from a lighted key when it is, respectively, positively or negatively related to food delivery (e.g., Wasserman, Franklin, \& Hearst, 1974). Signals in the different treatment conditions of the foregoing experiments represented differential predictors of reinforcement. Consequently, differences in eating latency may have reflected the distance of the bird from the magazine, which was located on the same wall as the key.

The present experiment provided a test of the motivation hypothesis by holding the bird's position constant as the signal-reinforcer contingency was manipulated. Birds were exposed, on different sessions, to contingent and noncontingent conditions. Superimposed on each session was a response-reinforcer contingency according to which reinforcers scheduled by the prevailing signalreinforcer contingency were delivered only if the bird pecked the key. As a result, the position of the bird's head was fixed immediately prior to reinforcer delivery, and only the vigor of the consummatory response was free to vary. On subsequent sessions, the response requirement was eliminated, and visual observations were made to assess variation in position.

\section{Method}

Subjects. Six naive White Carneaux hen culls were maintained at $75 \%$ of free-feeding weight.

Apparatus. The apparatus was identical to that used in the previous experiment.

Procedure. Magazine training was identical to that in Experiment 3 except that a criterion was established that required eating in 9 of 10 consecutive trials with latencies no greater than 5 sec on the 2-sec access trials. The first six subjects to meet the criterion within two sessions were selected from a total of nine birds tested. The houselight was continuously illuminated during magazine training and all subsequent sessions. In the following two sessions, additional unsignaled grain was presented on a random-time 50-sec (RT 50-sec) schedule ( $t=10 \mathrm{sec}$, $p=.20$ ) for 50 presentations. Access to grain, timed from the photobeam interruption, was $1 \mathrm{sec}$ on these and all subsequent grain presentations.

In the following session, the birds were trained to peck the key with an autoshaping procedure that was identical to the RT sessions, except that all grain deliveries were preceded by a 10-sec illumination of the key. In addition, a keypeck darkened the key and produced immediate grain delivery. In alternate sessions, the keylight signal was either red or three black vertical lines on a white ground. This procedure was terminated when 25 reinforcers were earned in the presence of each signal, and required no more than three sessions for any bird. Further keypeck training was provided on random-interval (RI) schedules. Sessions consisted of 30010 -sec segments, each segment com- prising five 2-sec bins. An RI 20-sec schedule $(p=.10)$ was in effect for two sessions, which terminated after 45 reinforcers were earned. Once set up, a reinforcer was held until collected. Each of the two key signals was used in one of these sessions. In the third session, the RI value was increased to $40 \mathrm{sec}(p=.05)$ and a limited hold requirement was introduced: $A$ reinforcer set up in a bin of a 10-sec segment was held only until the end of that segment. This schedule feature was required to permit control of reinforcer- delivery during the experiment proper. From the third session on, random blocks of two sessions (red or lines signal) were run until, in two sessions with each signal, a bird obtained at least $80 \%$ of the total available reinforcers in the segments in which they were set up, a criterion that was met in 8-10 days by all birds.

Up to this point, the birds were trained in the presence of the black enclosure described in Experiment 3. The enclosure was removed prior to experimental sessions. In these sessions, each 10 -sec segment was accompanied by one of two signals, S1 or $S 2$, on the key. The signals were either correlated (COR) or uncorrelated (UNC) with reinforcer delivery. In COR sessions, $\mathrm{S} 1$ and $\mathrm{S} 2$ components were associated with $\mathrm{RI}$ and extinction schedules, respectively, whereas in UNC sessions, both signals were associated with identical RI schedules. COR and UNC sessions were distinguished by the use of colors or line orientations as signals: For half the birds (Group RG), S1 and S2 were respectively, red and green colors in COR sessions and vertical and horizontal lines in UNC sessions. For the remaining birds (Group VH), the color and line-orientation cues were used on UNC and COR sessions, respectively, and S1/S2 designations remained the same. The alternation of COR and UNC sessions within birds was similar to a procedure employed by Redford and Perkins (1974) except that only S2 cues differed between sessions in that study.

There were $60 \mathrm{~S} 1$ and $240 \mathrm{~S} 2$ components in a session. Two different random sequences of signals were constructed with the restriction that no more than three $\mathrm{S} 1$ components occur in succession. Each sequence was used with each condition (COR and UNC) within random blocks of four sessions. The experiment was divided into three successive phases, with each phase consisting of 20 sessions.

Phase 1. An RI 40-sec schedule was in effect in S1 components in COR sessions and in both $\mathrm{S} 1$ and $\mathrm{S} 2$ components on UNC sessions. During sessions of either type, a reinforcer set up in a 10 -sec segment was cancelled if not obtained in that segment. Thus, programmed reinforcer frequency in S1 segments was equivalent in both session types. Expected numbers of reinforcers in $\mathbf{S 1}$ and S2 segments on UNC sessions were 15 and 60 , respectively, assuming at least one response in each 2 -sec bin.

Phase 2. Both signal-reinforcer contingency and total number of expected reinforcers varied between COR and UNC sessions in Phase 1 . The only change made in Phase 2 was to employ an RI 200-sec schedule $(p=.01)$ during both $S 1$ and $S 2$ in UNC sessions. Thus, expected reinforcer frequency (15 per session) was now equated between COR and UNC sessions.

Phase 3. Conditions during this phase were identical to those in Phase 2 except that the response-reinforcer contingency was eliminated. Reinforcers were presented on an RT 40-sec schedule in S1 components of COR sessions and on an RT 200-sec schedule in both components of UNC sessions. Scheduled reinforcers were delivered $1.5 \mathrm{sec}$ after the onset of a 2-sec bin. During the first and last four sessions of Phase 3, the location of the birds was observed and recorded. A zone was established, and defined as a vertical cylinder with a 1 -in. radius whose core was the line passing through the key and magazine apertures. The amount of time the bird's head was in the zone was determined in two $10-\mathrm{min}$ observation periods each session. Two observers making observations in separate periods agreed well in their time judgments $(r=.93)$.

During the three phases, the bin timer was stopped, but not reset, during reinforcer delivery. Reinforcement was available, prior to an eat, for a maximum of $30 \mathrm{sec}$. 


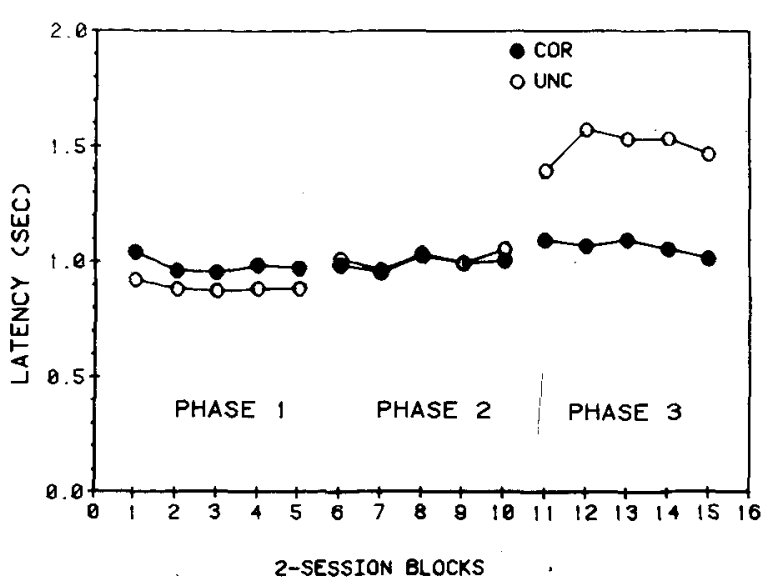

Figure 5. Mean food-peck latency in correlated (COR) and uncorrelated (UNC) sessions. Location constraint was present (left and middle panels) or absent (right panel). Reinforcer rates in COR and UNC sessions were unequal (left panel) or equal (middle and right panels).

\section{Results and Discussion}

Eating latency. Mean latencies for all birds during COR and UNC sessions are shown in Figure 5. Latencies were computed with the criteria applied in Experiment 3. Each point represents a 2-day block. For UNC sessions, comparisons of $\mathrm{S} 1$ and $\mathrm{S} 2$ latencies during Phase 1 showed no reliable difference (mean S1 and S2 latencies: .89 and $.88 \mathrm{sec}$, respectively). Therefore, on UNC sessions, S1 and S2 latencies were combined. An ANOVA indicated a significant difference between mean overall latencies of Groups RG and VH $[F(1,4)=8.08$, $\mathrm{p}<.05]$, with Group RG showing a shorter mean latency. This tendency, which persisted in all phases, was significant only in Phase 1. Groups did not interact with any variable in any phase.

Phase 1 results in the left panel indicate shorter latency in UNC sessions than in COR sessions, but the difference was not reliable $[F(1,4)=3.27]$. Therefore, the present results do not replicate the effect of the signal-reinforcer contingency found in the previous experiment. Design considerations apart from location constraint could be responsible for this discrepancy. Reinforcer rate was higher in UNC than in COR sessions. Experiment 3 data suggested that latency varies inversely with reinforcer rate, so it could be argued that rate masked contingency effects in the present study. However, such masking was not apparent in Experiment 3. An alternative possibility is based on the within-subject nature of the present manipulation. The fact that between-session differences in reinforcer rate were associated with different cues (color vs. lines) engendered a between-session stimulus-reinforcer contingency that may have opposed control by the withinsession contingencies. That is, within-session contingencies favored stronger behavioral tendencies in COR than in UNC sessions during S1 components, while the between-session contingency favored stronger tendencies overall in UNC sessions. Evidence of such an intersession contingency effect has been provided by Bloomfield (1967), who found that a multiple schedule with one component per day produced behavioral contrast-like differences in rate of keypecking.

In an attempt to reveal a within-session contingency effect, we eliminated the difference in reinforcer rates between sessions in Phase 2 by lowering the rate in UNC sessions to that on COR sessions. No contingency effect was observed during this phase, as shown in the middle panel of Figure 5. Latency in UNC sessions increased between phases $[t(5)=5.14, p<.01]$, providing a systematic replication of the reinforcer rate effect in Experiment 3. There was no reliable latency change between phases in COR sessions.

The failure to observe a contingency effect in Phases 1 and 2 when the bird's position was held constant implicates position as controlling the observed latency effect when both motivational factors and position are free to vary. In Phase 3 , the response-reinforcer contingency was eliminated, thereby removing the location constraint. An immediate lengthening of UNC over COR latencies was evident, as indicated in the right panel of Figure 5. Latencies in UNC sessions varied considerably relative to those in COR sessions, and the mean latency difference between conditions did not meet conventional reliability criteria in an ANOVA $[F(1,4)=4.36]$. However, the difference was in the same direction for all birds $(\mathrm{p}<.02$, sign test). An ANOVA including Phases 2 and 3 indicated a phase $X$ condition interaction $[F(1,4)=7.28$, $\mathrm{p}<.06]$, explained as an increase between phases in UNC latencies $[t(5)=2.84, p<.05]$, but no change in COR latencies $[t(5)=1.13]$.

Keypeck rate. Mean keypeck rate for all birds is shown in Figure 6. During Phase 1, clear differentiation between components was observed on COR sessions; an intermediate level of responding was maintained on both components of UNC sessions. In a comparison of

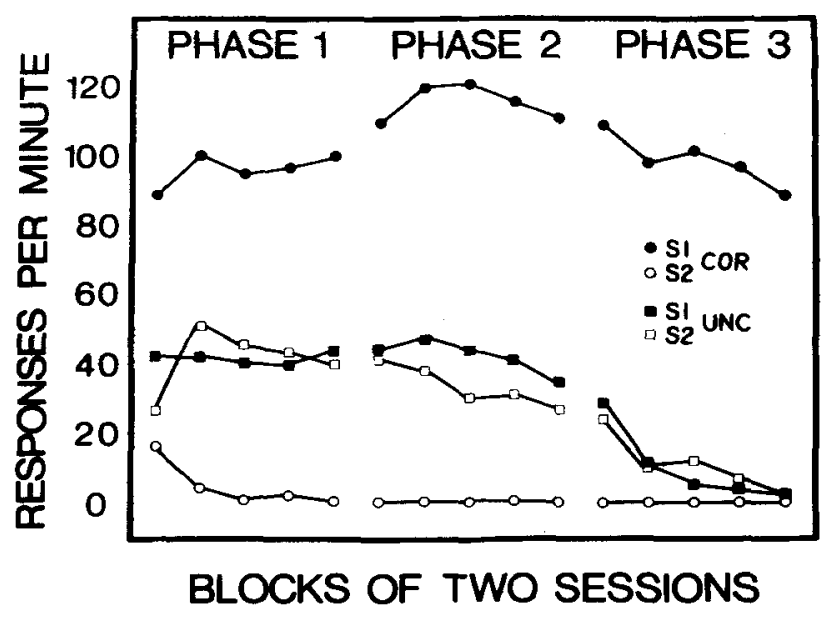

Figure 6. Mean keypeck rates during the three experiments phases. Rates are shown for $S 1$ and $S 2$ periods in each condition. 


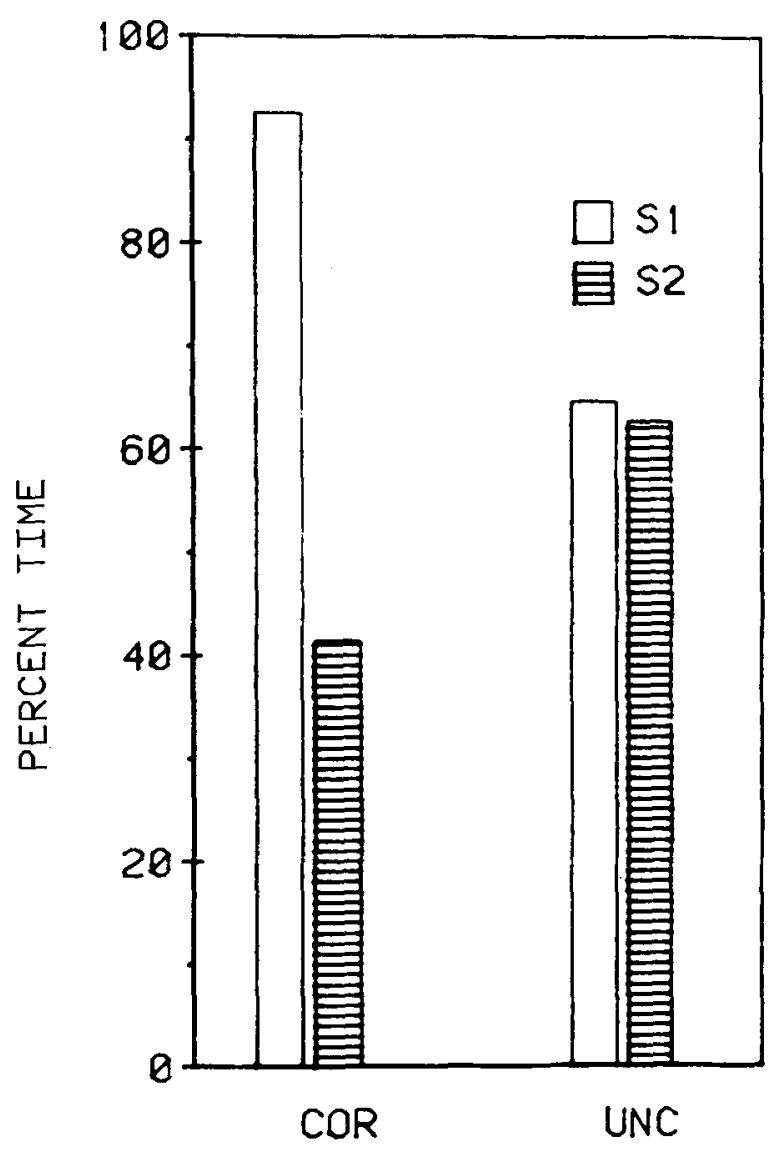

CONDITION

Figure 7. Mean percent time spent in the key/hopper zone during Phase 3 (no location constraint). Results are shown for $S 1$ and $S 2$ periods under each condition.

S1 responding between conditions, $\mathrm{COR}$ rate was reliably greater than $\mathrm{UNC}$ rate $[\mathrm{t}(5)=5.20, \mathrm{p}<.01]$. This difference is similar to the behavioral contrast reported by Redford and Perkins (1974). In both studies, "baseline" and "contrast" sessions alternated daily, and differences in rate were found between days in identical components of multiple schedules, as a result of differences in prevailing schedules in surrounding components. The difference between conditions in S1 rates increased between Phases 1 and 2 . A reliable increase in S1 rate was found between phases in COR sessions $[t(5)=3.79, p<.05]$, with no change in UNC sessions $(t<1)$. The $S 1$ rate increase could reflect a baseline rate change. Or it may reflect the introduction of an intersession stimulus-reinforcer contingency as UNC reinforcer rate was decreased across phases (Bloomfield, 1967). An implication of the latter alternative is that, in designs of this type, contrast-like effects are codetermined by inter- as well as intrasession contingencies.
When the response-reinforcer contingency was removed in Phase 3, response rates decreased similarly in all RT components, as shown in the right panel of the figure. The difference in $S 1$ rates between conditions was maintained $[t(5)=8.35, p<.01]$.

Position. Figure 7 presents the pooled results of visual observations made during Blocks 11 and 15 in Phase 3. The data were scored as the percent of total observation time spent in the criterion (key-magazine) zone for each component. In COR sessions, the birds spent more time in the zone during $S 1$ than during S2 components $[t(5)=5.40, p<.01]$. In UNC sessions, the birds spent a greater proportion of time in the criterion region than out of it, but their positions did not differ between components $(t<1)$. Finally, the birds spent more time in the zone in COR than in UNC sessions during component $\mathrm{S} 1[\mathrm{t}(5)=8.34, \mathrm{p}<.01]$. The latter difference strongly suggests that food-peck latency effects were mediated by variations in the bird's distance from the site of food.

\section{GENERAL DISCUSSION}

The results of the four experiments indicate a general susceptibility of eating latency in the pigeon to variations in the CS-US relation defined either in terms of the interstimulus interval or the conditional relations between those events. Signals that are strong predictors of food promote short latencies. This statement holds only for the free-ranging pigeon, however. When location constraints were imposed, latency was marginally sensitive to reinforcer frequency, and was apparently invariant with respect to the CS.US contingency. When the location constraint was lifted, contingency-related latency differences emerged. Visual observations made during that phase indicated that birds tended to position themselves closer to the CS/US site when a predictive cue was present than when an uninformative stimulus was present.

Not all of the systematic variation in latency is readily attributable to associative mechanisms. In Experiment 1, latency was nonmonotonically related to ISI values. The increase in latency beyond the 5 -sec ISI suggests that birds were farther from the magazine during longer than during shorter ISIs, and is in line with a conditioning account. However, the decrease in latency from 1 to $2 \mathrm{sec}$ values may represent a performance effect that reflects the bird's minimum travel time to the hopper from its average position in the chamber during the ITI. A second finding concerns the test phase of Experiment 3 in which eat latencies for Groups $\mathrm{C} 12$ and $\mathrm{C} 60$ were longer during unsignaled (S0) than during signaled (S1) periods (see Figure 4). Latencies in SO periods could reflect control by back. ground cues of conditioned approach to the intelligence panel during the zero correlation condition, an inference supported by the results of Group E. However, the 
latency difference between S1 and So periods is not easily accommodated by this sort of analysis, since background cues were also present during $S 1$, and $S 1$ cues would not be expected to exert control under these conditions (Rescorla \& Wagner, 1972). Alternatively, the data could imply that under zero correlation conditions context cues are excitatory, and the CS is not neutral, but inhibitory. While an associative account cannot be ruled out, other interpretations, such as disruption of ongoing behavior by keylight onset, seem no less plausible.

Associative effects upon UR latency appear to be mediated solely by CS-related activities. It is likely that key-directed behavior, including pecking, was the terminal performance during CS periods. Although the two measures were generally related, it is unlikely that keypecking per se determined UR latency. Latency effects were observed in the near absence of keypecking behavior (Experiment 2), and latencies on positive trials remained stable as keypecking systematically varied (Experiment 4). A plausible account is that the CS-US relation induces approach tendencies toward cues that predict the US, and withdrawal from cues predicting no-US, relative to uninformative cues, as suggested by our observations (cf. Figure 7) and previous research (e.g., Hearst \& Franklin, 1977; Jenkins \& Boakes, 1973; Wasserman et al., 1974). These tendencies, in turn, placed the bird at different distances from the food magazine in the present situation, as reflected in latency.

The preceding account assumes that as the bird advances toward the key it places itself closer to the magazine as well, owing to their locations on the same wall of the chamber. It is possible, however, that the primary movement is toward the magazine itself. Goaltracking, that is, conditioned approach to the site of reinforcer delivery, has been reported for rats with both solid-food (Boakes, 1977) and liquid (Farwell \& Ayres, 1979) reinforcement. Our visual observations did not distinguish between key- and hopper-directed behaviors. However, a number of considerations support keydirected behavior as the primary factor in the present study. Peden, Browne, and Hearst (1977) presented grain to pigeons following presentation of a localized visual signal only if the bird did not approach the signal. For two groups of birds, the signal and food sources were well separated on different walls of a long chamber. During signal presentation, persistent approaches to the signal ( $65 \%$ of the trials) were exhibited by these birds, although magazine approaches were seen just prior to grain delivery on some trials. Dominant CS-directed behavior has also been reported in rats when CS and US sites are well separated (Buzsáki, 1982).

When CS and US are located on the same wall, as in the present case, US approach could be facilitated. Gibbon, Farrell, Locurto, Duncan, and Terrace (1980) have reported that rate of keypecking either remains constant or decreases as the ISI elapses under $100 \%$ reinforcement conditions in autoshaping. They suggest that this pattern reflects the bird's abandonment of the key for the magazine toward the end of the ISI. However, under partial reinforcement conditions, rate increased to a maximum trial level at the end of the ISI. These observations were made under conditions similar to those of the correlated conditions in Experiments 3 and 4. During S1 components, higher rates of pecking in those conditions than in uncorrelated conditions strongly suggest that birds were closer to the key on correlated sessions upon food delivery.

Approaches to the key rather than the magazine might also be expected from discriminative stimulus properties of magazine cues, a factor proposed in previous analyses (e.g., Farwell \& Ayres, 1979) as an important determinant of goal-tracking tendency. Specifically, in the present studies food was available only when the magazine was illuminated. Therefore, approach to the goal may have come under the control of the magazine light. In this case, little goal-tending would be expected to compete with approaches to the key during CS periods.

A fourth argument favoring key-directed behavior is based upon the results of Experiment 4. During Phases 1 and 2 , the bird's head was, perforce, at the key upon grain delivery. With the elimination of the responsereinforcer contingency, the bird was free to move toward the magazine on $\mathrm{S} 1$ trials prior to grain delivery in the COR condition. However, no decrease in latency was observed on those trials in Phase 3. Instead, a contingency effect was produced by an increase in latency in UNC sessions. Finally, we rarely detected outright hopper-directed activity in the absence of grain, in our visual observations. In sum, under conditions of the present studies, approach behavior mediating the effect of the CS-US relation upon latency is better characterized as sign-tracking than goal-tracking.

The present findings do not encourage a version of expectancy theory that endows expectancies with motivation properties that energize prevailing response tendencies, at least not for behaviors that are USdirected. Experiment 4 provided no evidence of UR potentiation exclusive of positional factors. Various distinctions have been made between consummatory and preconsummatory behaviors in appetitive situations (e.g., Bindra, 1974; Buzsáki, 1982; Konorski, 1967), with emphasis on functional differences between these classes. In Bindra's model, for example, only the latter (preparatory) behaviors are subject to incentive influences. The present results with respect to key- vs. food-directed behaviors support those distinctions.

A long-standing issue in expectancy theory has been the mapping of expectancies onto behavior as exemplified by situations ranging from "behaviorally silent" learning (Dickinson, 1980) to CS/US interaction effects (e.g., Timberlake \& Grant, 1975). The usefulness of expectancy theory has not been in predicting behavior, but rather in directing attention to the operations that 
make one event a good predictor of another. Behavioral outcomes that reflect learning are, for the most part, a matter of empirical determination. Generally, however, they accrue to the predictor event, as is evident in autoshaping with pigeons, not the predicted one. The relevance of the present study to the phenomenon of UR modification is to focus attention on what the subject does, not only what it knows, in the presence of the CS.

\section{REFERENCES}

BAXter, R. Diminution and recovery of the UCR in delayed and trace classical GSR conditioning. Journal of Experimental Psychology, 1966, 71, 447-451.

Bentsch, G. S., \& Becker, R. An inexpensive food-peck recorder for pigeons. Journal of the Experimental Analysis of Behavior, 1973, 20, 71-72.

Bindra, D. A motivational view of learning, performance, and behavior modification. Psychological Review, 1974, 81, 199-213.

Bloomfield, T. M. Behavioral contrast and relative reinforcement frequency in two multiple schedules. Journal of the Experimental Analysis of Behavior, 1967, 10, 151-158.

Boakes, R. A. Performance on learning to associate a stimulus with positive reinforcement. In H. Davis \& $H$. M. B. Hurwitz (Eds.), Operant-Pavlovian interactions. Hillsdale, N.J: Erlbaum, 1977.

Bolles, R. C. Reinforcement, expectancy, and learning. Psychological Review, 1972, 79, 394-409.

Brown, P. L., \& Jenkins, H. M. Auto-shaping of the pigeon's key peck. Journal of the Experimental Analysis of Behavior, $1968,11,1-8$.

Burt, J. S., \& Westreook, R. F. Second-order autoshaped key pecking based on an auditory stimulus. Journal of the Experimental Analysis of Behavior, 1980, 34, 305-318.

Buzsiki, G. The "Where is it?" reflex: Autoshaping the orienting response. Journal of the Experimental Analysis of Behavior, 1982, 37, 461-484.

Cowles, J. T., \& Nissen, H. W. Reward-expectancy in delayed responses of chimpanzees. Journal of Comparative Psychology, $1937,24,345-358$.

Dickinson, A. Contemporary animal learning theory. Cambridge: Cambridge University Press, 1980.

Donegan, N. H. Priming-produced facilitation or diminution of responding to a Pavlovian unconditioned stimulus. Journal of Experimental Psychology: Animal Behavior Processes, 1981, 7, 295-312.

Edwards, C. A., Jagielo, J. A., Zentall, T. R., \& Hogan, D. E. Acquired equivalence and distinctiveness in matching to sample by pigeons: Mediation by reinforcer-specific expectancies. Jotrnal of Experimental Psychology: Animal Behavior Processes, 1982, 8, 244-259.

Farwell, B. J., \& Ayres, J. J. B. Stimulus-reinforcer and response-reinforcer relations in the control of conditioned appetitive headpoking ("goal-tracking") in rats. Learning and Motivation, 1979, 10, 295-312.

Gibbon, J., \& Balsam, P. Spreading association in time. In C. M. Locurto, H. S. Terrace, \& J. Gibbon (Eds.), Autoshaping and conditioning theory. New York: Academic Press, 1981.

Gibson, J., \& Church, R. M. Time left: Linear vs. logarithmic subjective time. Journal of Experimental Psychology: Animal Behavior Processes, 1981, 7, 87-108.

Gibion, J., Farrell, L., Locurto, C. M., Duncan, H., \& Tenrace, H. S. Partial reinforcement in autoshaping with pigeons.Animal Learning \& Behavior, 1980, 8, 45-59.

Grevert, P., \& Moone, J. W. The effect of unpaired US presentations on conditioning of the rabbit's nictitating membrane response: Consolidation or contingency? Psychonomic Science, $1970,20,177-179$.

Grings, W. W. Preparatory set variables related to classical conditioning of autonomic responses. Psychological Review, $1960,67,243-252$.

Grings, W. W., \& Schell, A. M. UCR diminution in trace and delay conditioning. Journal of Experimental Psychology, 1969, 79, 246-248.

Hearst, E., \& Franklin, S. R. Positive and negative relations between a signal and food: Approach-withdrawal behavior to the signal. Journal of Experimental Psychology: Animal Behavior Processes, 1977, 3, 37-52.

Hearst, E., \& Jenkins, H. M. Sign-tracking: The stimulusreinforcer relation and directed action. Austin, Tex: Psychonomic Society, 1974.

Hilgard, E. R., \& Marquis, D. M. Conditioning and learning. New York: Appleton-Century, 1940.

Hupka, R. B., Kwaterski, S. E., \& Moore, J. W. Conditioned diminution of the UCR: Differences between the human eyeblink and the rabbit nictitating membrane response. Journal of Experimental Psychology, 1970, 83, 45-51.

Jenkins, H. M., \& Bonkes, R. A. Observing stimulus sources that signal food or no food. Journal of the Experimental Analysis of Behavior, 1973, 20, 197-207.

Kamin, L. J. Predictability, surprise, attention, and conditioning. In B. A. Campbell \& R. M. Church (Eds.), Punishment and aversive behavior. New York: Appleton-Century-Crofts, 1969.

Kimble, G. A., \& Durort, R. H. The associative factor in eyelid conditioning. Journal of Experimental Psychology, 1956, 52, 386-391.

Kimble, G. A., \& Ost, J. W. A conditioned inhibitory process in eyelid conditioning. Journal of Experimental Psychology, $1961,61,150-156$.

KIMMEL, H. D. Inhibition of the unconditioned response in classical conditioning. Psychological Review, 1966, 73, 232-240.

Kimmel, H. D., \& Pennypacker, H. S. Conditioned diminution of the unconditioned response as a function of the number of reinforcements. Journal of Experimental Psychology, 1962, 64, 20-23.

KonORsk1, J. Integrative activity of the brain. Chicago: University of Chicago Press, 1967.

Leyland, C. M., \& Mackintosh, N. J. Blocking of first- and second-order autoshaping in pigeons. Animal Learning \& Behavior, 1978, 6, 391-394.

Morrow, M. C. Recovery of conditioned UCR diminution following extinction. Journal of Experimental Psychology, 1966, 71, 884-888.

Mowrer, O. H. Preparatory set (expectancy)-some methods of measurement. Psychological Monographs, 1940, 52(Whole No. 233).

Peden, B. F., Browne, M. P., \& Hearst, E. Persistent approaches to a signal for food despite food omission for approaching. Journal of Experimental Psychology: Animal Behavior Processes, 1977, 3, 377-399.

Perkins, C. C., Jr., Beavers, W. O., Hancock, R. A., Hemmendinger, P. C., Hemmendinger, D., \& Ricci, J. A. Some variables affecting rate of key pecking during responseindependent procedures (autoshaping). Journal of the Experimental Analysis of Behavior, 1975, 24, 59-72.

Redford, M. E., \& Perkins, C. C., Jr. The role of autopecking in behavioral contrast. Journal of the Experimental Analysis of Behavior, 1974, 21, 145-150.

Resconla, R. A. Pavlovian conditioning and its proper control procedures. Psychological Review, 1967, 74, 71-80.

Rescorla, R. A., \& Wagner, A. R. A theory of Pavlovian conditioning: Variations in the effectiveness of reinforcement and nonreinforcement. In A. H. Black \& W. F. Prokasy (Eds.), Classical conditioning II: Current research and theory. New York: Appleton-Century-Crofts, 1972.

Salafia, W. R., Daston, A. P., Bartosiak, R. S., Hurley, J., 
\& Martino, L. J. Classical nictitating membrane conditioning in the rabbit (Oryctolagus cuniculus) as a function of unconditioned stimulus locus. Journal of Comparative and Physiological Psychology, 1974, 86, 628-636.

Schwartz, B., \& Gamzu, E. Pavlovian control of operant behavior: An analysis of autoshaping and its implications for operant conditioning. In W. K. Honig \& J. E. R. Staddon (Eds.), Handbook of operant conditioning. Englewood Cliffs, N.J: Prentice-Hall, 1977.

Sheafor, P. J., \& Gormezano, I. Conditioning the rabbit's (Oryctolagus cuniculus) jaw-movement response: US magnitude effects on URs, CRs, and pseudo-CRs. Journal of Comparative and Physiological Psychology, 1972, 81, 449-456.

Spooner, A., \& Kelloga, W. N. The backward conditioning curve. American Journal of Psychology, 1947, 60, 321-334.

Tномаs, E. Role of postural adjustments in conditioning of dogs with electrical stimulation of the motor cortex as the unconditioned stimulus. Journal of Comparative and Physiological Psychology, 1971, 76, 187-198.

Timberlake, W., \& Grant, D. L. Auto-shaping in rats to the presentation of another rat predicting food. Science, 1975, 190, 690-692.

TinkLe paugh, 0 . L. An experimental study of representational factors in monkeys. Journal of Comparative Psychology, 1928, $8,197-236$.

Tomie, A. Interference with autoshaping by prior context conditioning. Journal of Experimental Psychology: Animal Behavior Processes, 1976, 2, 323-334.

Wagnen, A. R. Priming in STM. In T. J. Tighe \& R. N. Leaton (Eds.), Habituation. Hillsdale, N.J: Erlbaum, 1976.

WAGNER, A. R. Expectancies and the priming of STM. In S. H. Hulse, H. Fowler, \& W. K. Honig (Eds.), Cognitive processes in animal behavior. Hillsdale, N.J: Erlbaum, 1978.

Wasserman, E. A., Franklin, S. R., \& Hearst, E. Pavlovian appetitive contingencies and approach versus withdrawal to conditioned stimuli in pigeons. Journal of Comparative and Physiological Psychology, 1974, 86, 616-627.

WoodruFF, G., \& Williams, D. R. The associative relation underlying autoshaping in the pigeon. Journal of the Experimental Analysis of Behavior, 1976, 26, 1-13.

ZAMBLE, E. Augmentation of eating following a signal for feeding in rats. Learning and Motivation, 1973, 4, 138-147.

(Manuscript received August 13, 1982; revision accepted for publication June 12, 1983.) 